\title{
Prevalence of metabolic syndrome in a sample of population in Erbil city, Iraq
}


changes to the Arab world including Iraq. There has been a recent concern about chronic non-communicable diseases (NCDs) in Iraq. The country is undergoing an epidemiological transition with an increasing burden of chronic NCDs. According to chronic non-communicable disease risk factor survey in 2006 in Iraq, two-thirds $(66.9 \%)$ of the peoples from 25-65 years old were found to be overweight and one-third (32.9\%) of them were found to be obese. ${ }^{5-6}$ Erbil, the capital of Iraqi Kurdistan moving toward changes in the lifestyle similar to that of Western cultures, is likely to face increasing challenges of preventing chronic diseases including cardiovascular disease and diabetes. Little information exists on the prevalence of the MetS in Erbil, because Ministry of Health (MOH) / Iraq with support and cooperation of World Health Organization, conducted a noncommunicable disease risk factor survey in 2006 covering all Iraqi governments except Erbil city, probably because of financial and or/ political reasons. There is inadequate information about accurate estimates of MetS, $\mathrm{MOH}$ statistics from hospital-based data and routinely collected information showed that such diseases represent most of the ten leading causes of mortality for the age groups of five years and over for the past years. ${ }^{5}$ Such data are important for planning national chronic disease treatment and prevention programs. Based on these facts, authors hypothesize that MetS prevalence in Erbil city is high due to the above-mentioned causes. The authors, therefore, conducted the present study to estimate the prevalence of MetS with their associated risk factors among a sample of peoples in Erbil city between the periods from March $1^{\text {st }}, 2013$ to April $1^{\text {st }}, 2014$. More specifically, the main objectives of this study included determining the frequency of MetS with their associated risk factors such as cigarette smoking and alcohol consumption, estimating the prevalence of MetS by certain demographic features such as age groups, gender and occupation and finding out the association between MetS and different sociodemographic variables.

\section{Methods}

\section{Design, setting and time of the study:}

This cross-sectional analytic study was carried out in Erbil city, between the periods from March $1^{\text {st }}, 2013$ to April $1^{\text {st }}$, 2014.

\section{Sample size and sample selection:}

A convenience sample of 566 persons was selected for this study.

\section{Participants:}

This study included all adult participants of more than 18 years old in the following settings:

1. A sample of 313 medical staff from Rizgary Teaching Hospital, Rozh-Halat Emergency Hospital, Maternity Hospital, Rozh-awa Emergency Hospital, Nanakaly Hospital, Hawler Teaching Hospital and Malafandy Health Center.

2. A sample of 200 patients of surgical outpatients department of Rozh-Halat Emergency Hospital.

3. A sample of 53 peoples from Al-Hikma Education center for the Holy Quran studies.

\section{Exclusion Criteria:}

Participants with any acute, chronic diseases, malignant diseases or those who are on regular medication during the study (apart from hypertension, diabetes mellitus, and hyperlipidemia) were excluded from the study. Pregnant ladies and those operated upon recently were excluded from the study, too. Smoking habits were classified into smokers and non-smokers and ex-smokers were also excluded from the study.

\section{Questionnaires:}

A structured direct interview using interviewer-administered questionnaire methods was applied. The questionnaire contained questions on demographics, social and characteristics as well as questions regarding diagnostic criteria of MetS. 


\section{Physical examination:}

Weight and height, waist circumference, hip circumference, blood pressure, respiratory rate, and pulse rate were taken by the researcher. A patient was considered as "overweight or obese" according to Classification of the WHO and International Obesity Task Force. $^{7}$ The weight of patients was measured in kilograms using digital anthropometric scale; an average of one kilogram for patients was estimated to be deducted from patients' weight to replace their clothes. The height of patients was measured in centimeters using a plastic measuring tape which was fixed on the wall and the patients standing bare foots with backs against the wall and their heels touching the wall. The waist measurement was taken at the midpoint between the lowest rib and the top of the hip bone (iliac crest) in the mid-axillary line, while the hip circumference measurement was taken from the widest portion of the buttocks over the pubic area. ${ }^{7}$ To classify underweight, overweight and obesity in adults, the body mass index (BMI) was calculated by the weight in kilograms divided by the square of the height in meters $(\mathrm{kg} / \mathrm{m} 2)$ : underweight $(\mathrm{BMl}<18.6)$, normal weight (BMI: 18.6-24.9), overweight (BMI: 2529.9), obese class I (BMI: 30-34.9), obese class II (BMI: 35-39.9) and obese class III (BMI: >40). ${ }^{8}$

\section{Laboratory investigations:}

Random blood sugar, cholesterol level, triglyceride level (TG), Low-Density Lipoprotein (LDL) and High-Density Lipoprotein (HDL) were investigated. Blood sample was taken by a trained health staff and was centrifuged directly after collection and the serum either immediately analyzed or stored at $\leq-20^{\circ} \mathrm{C}$ in the Medical Research Centre, a research center affiliated with Hawler Medical University. Serum total cholesterol (TC) high-density lipoprotein cholesterol (HDL-C), low-density lipoprotein cholesterol (LDL-C), triglyceride (TG) and serum glucose were measured using the commercially available kits
(Enzymatic colorimetric method used according to Trinder method by spectrophotometer machine SIEMENS German 2008), and serum glucose measured through laboratory long method.

Diagnostic criteria of MetS:

Definition of metabolic syndrome was based on the presence of the following criteria: ${ }^{8-12}$

1. Central obesity, defined as a waist circumference greater than $102 \mathrm{~cm}$ for men, and $88 \mathrm{~cm}$ for women.

2. Plus, any two of the following factors or history of prior treatment for this factor:

- Elevated fasting triglyceride level > 150 $\mathrm{mg} / \mathrm{dl}$. (1.7 mmol/L)

- Reduced HDL cholesterol $<40 \mathrm{mg} / \mathrm{dl}$. $(1.0 \mathrm{mmol} / \mathrm{L})$ for men, or $<50 \mathrm{mg} / \mathrm{dl}$. $(1.3 \mathrm{mmol} / \mathrm{L})$ for women

- Elevated blood pressure (BP): systolic BP

$>130$ or diastolic BP >85 mm Hg.

- Elevated fasting plasma glucose $\geq 100$ $\mathrm{mg} / \mathrm{dl}(5.6 \mathrm{mmol} / \mathrm{L})$.

- Or patient receiving treatment for the above conditions.

\section{Ethical consideration}

All participants provided informed consent before participating in the study, and the research protocol was reviewed and approved by the Ethical Committee of the College of Medicine, Hawler Medical University. The anonymity of the participants was preserved.

\section{Data entry and data analysis:}

The statistical package of the social science software (version 19.1) was used for data entry and analysis. Mean ( \pm SD) and statistical tests like Chi-square tests for both numerical and categorical variables were used, respectively. A $P$ value $\leq 0.05$ was regarded as statistically significant.

\section{Results}

Five hundred sixty-six participants have been recruited in this study, $289(51.1 \%)$ male and $277(48.9 \%)$ female. The minimum age was 19; the maximum age was 80 , with mean ( \pm SD) of $29.88 \pm 13.33$ years old. The majority of participants were married 448 (79.2\%), from inside Erbil city 
$482(85.2 \%)$ and employed 402 (71.02\%). Meanwhile housewives constituted $24.02 \%$. Minimum BMI was 16.87 , maximum was 47.06 , mean $( \pm S D)$ was $28.21 \pm$ 5.50. The proportion of obese participants was $35.7 \%$, and the proportion of overweight and obese was $68.7 \%$. Females found to be more obese than males. The association between BMI and gender was statistically significant. Minimum waist circumference was 61 , maximum was 140 , mean $( \pm$ SD) was $90.22 \pm 13.16,144$ $(25.4 \%)$. Females were found to have waist a circumference $>88 \mathrm{~cm}$ compared to male waist circumference $>102 \mathrm{~cm}$ of $52(9.2 \%)$ with significant statistical association between waist and gender $(P<0.001)$ as shown in Table 1, 2 and 3.

Table 1: Descriptive statistics of some MetS variables.

\begin{tabular}{|c|c|c|c|c|}
\hline Variables & Minimum & Maximum & Mean & SD \\
\hline \multicolumn{5}{|l|}{ Anthropometric: } \\
\hline Weight (Kg) & 40 & 135 & 76.6 & 14.9 \\
\hline Height $(\mathrm{Cm})$ & 138 & 192 & 165.05 & 9.3 \\
\hline Waist Circumference $(\mathrm{Cm})$ & 61 & 140 & 90.2 & 13.1 \\
\hline Hip Circumference (Cm) & 70 & 162 & 103.7 & 12.9 \\
\hline Body Mass Index & 16.87 & 47.06 & 28.2 & 5.5 \\
\hline \multicolumn{5}{|l|}{ Clinical: } \\
\hline Systolic Blood Pressure & 70 & 183 & 134.4 & 24.8 \\
\hline Diastolic Blood Pressure & 45 & 120 & 74.9 & 12.2 \\
\hline \multicolumn{5}{|l|}{ Laboratory: } \\
\hline Blood Sugar & 73 & 450 & 115.2 & 52.4 \\
\hline Serum Cholesterol & 80 & 421 & 186.2 & 57.7 \\
\hline Low Density Lipoprotein & 11 & 591 & 112.06 & 48.6 \\
\hline Triglyceride & 26 & 897 & 186.8 & 116.5 \\
\hline $\mathrm{HDL}$ & 16 & 127 & 39.8 & 10.8 \\
\hline
\end{tabular}

Table 2: BMI category by gender

\begin{tabular}{|c|c|c|c|c|c|c|c|}
\hline \multirow{3}{*}{ BMI Category } & \multicolumn{4}{|c|}{ Gender } & \multirow{2}{*}{\multicolumn{2}{|c|}{ Total }} & \multirow{3}{*}{$P$ value } \\
\hline & \multicolumn{2}{|c|}{ Male } & \multicolumn{2}{|c|}{ Female } & & & \\
\hline & No. & $(\%)$ & No. & $(\%)$ & No. & $(\%)$ & \\
\hline Underweight $(\mathrm{BMI}<18.6)$ & 6 & $(50)$ & 6 & $(50)$ & 12 & $(2.1)$ & \\
\hline $\begin{array}{l}\text { Normal weight } \\
\text { (BMI:18.6-24.9) }\end{array}$ & 85 & $(51.5)$ & 80 & $(48.5)$ & 165 & $(29.2)$ & \\
\hline $\begin{array}{l}\text { Overweight } \\
\text { (BMI: 25-29.9) }\end{array}$ & 118 & $(63.1)$ & 69 & $(36.9)$ & 187 & (33) & \\
\hline $\begin{array}{l}\text { Obese Class I } \\
\text { (BMI: } 30-34.9 \text { ) }\end{array}$ & 62 & $(45.3)$ & 75 & $(54.7)$ & 137 & $(24.2)$ & $<0.001$ \\
\hline $\begin{array}{l}\text { Obese Class II } \\
\text { (BMI: } 35-39.9 \text { ) }\end{array}$ & 15 & $(29.4)$ & 36 & $(70.6)$ & 51 & (9) & \\
\hline $\begin{array}{l}\text { Obese Class III } \\
\text { (BMI: >40) }\end{array}$ & 3 & $(21.4)$ & 11 & $(78.6)$ & 14 & $(2.5)$ & \\
\hline Total & 289 & $(51.1)$ & 277 & $(48.9)$ & 566 & $(100)$ & \\
\hline
\end{tabular}

Table 3: Prevalence of MetS by waist.

\begin{tabular}{|c|c|c|c|c|c|c|}
\hline \multirow[b]{2}{*}{ Waist } & & \multicolumn{2}{|c|}{ MetS } & \multicolumn{2}{|c|}{ No MetS } & \multirow[b]{2}{*}{ Total } \\
\hline & & No. & $\%$ & No. & $\%$ & \\
\hline \multirow[t]{2}{*}{ Male } & $<102$ & 0 & (0) & 237 & $(100)$ & 237 \\
\hline & $>102$ & 47 & $(90.4)$ & 5 & $(9.6)$ & 52 \\
\hline \multirow[t]{2}{*}{ Female } & $<88$ & 0 & (0) & 133 & (100) & 133 \\
\hline & $>88$ & 126 & $(87.5)$ & 18 & (12.5) & 144 \\
\hline \multicolumn{2}{|c|}{ Grand total } & 173 & (30.6) & 393 & (69.4) & 566 \\
\hline
\end{tabular}


Prevalence of MetS: The prevalence of MetS in the studied sample was 173 $(30.6 \%)$; females prevalence was outstanding126 $(45.5 \%)$ males prevalence $47(16.3 \%)$ with a significant association between prevalence of MetS and gender (Table 4). Table 5 shows that the older the participant, the higher the prevalence of MetS with a significant association between prevalence of MetS and their age. Regarding educational status, it's found that prevalence of MetS ranges from illiterates $97 / 215(45.1 \%)$ to university level $27 / 144(18.7 \%)$ with a statistically significant association between MetS and educational status $(P<0.001)$. Married persons outnumber 158/448 (35.3\%) singles $15 / 118(12.7 \%)$ with significant association ( $P$ <0.001). No significant association was found between urban $139 / 482(28.8 \%)$ and rural $34 / 84(40.5 \%)$ with $(P=0.1)$ and between smokers $23 / 58$ $(39.7 \%)$ and nonsmokers 150/508 (29.5\%) with $(P=0.11)$ as shown in Table 6 .

Table 4: MetS by gender.

\begin{tabular}{lcccccc}
\hline \multirow{2}{*}{ Gender } & \multicolumn{2}{c}{ MetS } & \multicolumn{2}{c}{ No MetS } & Total & \multirow{2}{*}{$\boldsymbol{P}$ value } \\
\hline Male & 47 & $(16.3)$ & 242 & $(83.7)$ & 289 & \\
Female & 126 & $(45.5)$ & 151 & $(54.5)$ & 277 & $<0.001$ \\
Total & 173 & $(30.6)$ & 393 & $(69.4)$ & 566 & \\
\hline
\end{tabular}

Table 5: Age groups by MetS.

\begin{tabular}{lcccccc}
\hline \multirow{2}{*}{ Age Category } & \multicolumn{2}{c}{ MetS } & \multicolumn{2}{c}{ No MetS } & \multirow{2}{*}{ Total } & \multirow{2}{*}{$\boldsymbol{P}$ value } \\
\hline$<20$ & No. & $(\mathbf{\%})$ & No. & $(\%)$ & & \\
$20-40$ & 15 & $(22.4)$ & 52 & $(77.6)$ & 67 & \\
$>40$ & 95 & $(27.9)$ & 246 & $(72.1)$ & 341 & 0.008 \\
Total & 63 & $(39.9)$ & 95 & $(60.1)$ & 158 & \\
\hline
\end{tabular}

Table 6: Demographic and social variables by MetS.

\begin{tabular}{|c|c|c|c|c|c|c|c|}
\hline \multirow{2}{*}{\multicolumn{2}{|c|}{$\begin{array}{l}\text { Demographic and social } \\
\text { Variables }\end{array}$}} & \multicolumn{2}{|c|}{ MetS } & \multicolumn{2}{|c|}{ No MetS } & \multirow[b]{2}{*}{ Total } & \multirow[b]{2}{*}{$P$ value } \\
\hline & & No. & (\%) & No. & (\%) & & \\
\hline \multirow[t]{6}{*}{ Education } & Illiterate & 97 & $(45.1)$ & 118 & (54.9) & 215 & \multirow{6}{*}{$<0.001$} \\
\hline & Primary & 9 & $(29)$ & 22 & $(71)$ & 31 & \\
\hline & Secondary & 23 & (27.7) & 60 & (72.3) & 83 & \\
\hline & Institute & 17 & (18.3) & 76 & (81.7) & 93 & \\
\hline & University & 26 & (18.7) & 113 & (81.3) & 139 & \\
\hline & Postgraduate & 1 & $(20)$ & 4 & $(80)$ & 5 & \\
\hline \multirow[t]{2}{*}{ Marital status } & Married & 158 & (35.3) & 290 & $(64.7)$ & 448 & \multirow{2}{*}{$<0.001$} \\
\hline & Single & 15 & (12.7) & 103 & (87.3) & 118 & \\
\hline \multirow[t]{3}{*}{ Residence } & Urban & 135 & (28.8) & 334 & $(71.2)$ & 469 & \multirow{6}{*}{0.1} \\
\hline & Rural & 34 & $(40.5)$ & 50 & (59.5) & 84 & \\
\hline & Other city & 4 & $(30.8)$ & 9 & (69.2) & 13 & \\
\hline Cigarette & Non smoker & 150 & (29.5) & 358 & $(70.5)$ & 508 & \\
\hline \multirow[t]{2}{*}{ smoking } & Smoker & 23 & (39.7) & 35 & $(60.3)$ & 58 & \\
\hline & Total & 173 & $(30.6)$ & 393 & $(69.4)$ & 566 & \\
\hline \multirow[t]{4}{*}{ Occupation } & Employed & 86 & (22.2) & 302 & (77.8) & 388 & \multirow{5}{*}{$<0.001$} \\
\hline & Unemployed & 9 & (32.1) & 19 & $(67.9)$ & 28 & \\
\hline & Student & 5 & (35.7) & 9 & $(64.3)$ & 14 & \\
\hline & Housewife & 73 & (53.7) & 63 & $(46.3)$ & 136 & \\
\hline Total & & 173 & (30.6) & 393 & $(69.4)$ & 566 & \\
\hline
\end{tabular}


Family history (FH) and MetS:

$\mathrm{FH}$ of DM $74 / 174 \quad(30.1 \%), \mathrm{FH}$ of hyperlipidemia (FHL) 38/112 (33.9\%), FH of hypertension (HTN) 111/328 (33.8\%) and $\mathrm{FH}$ of obesity 99/274 (36.1\%) were significantly associated with prevalence of MetS $(P=0.029, P<0.001, P=0$. and $P=$ 0.005 , respectively) as shown in Table 7 .

\section{Discussion}

The aim of this study was to estimate the prevalence of MetS among a sample of peoples in Erbil city. $\mathrm{MOH}$ figures about MetS risk factors, especially obesity, DM and cardiovascular complications following untreated MetS are increasing in our country. ${ }^{5}$ This change in prevalence is probably due to urbanization, economic growth, westernization of our diet, physical inactivity, irregular meal time and increased stress. ${ }^{13}$ This study showed that the proportion of obesity among participants was $35.7 \%$ having $\mathrm{BMI} \geq 30 \mathrm{~kg} / \mathrm{m}^{2}$ and the proportion of overweight and obesity was $68.7 \%$. According to the International Diabetes Federation (IDF) classification of MetS, the prevalence of MetS in this study was $30.6 \%$ which is similar to the prevalence of MetS in Iran $32.1 \%,{ }^{14}$ but higher than that of USA $25 \%$ while it is much lower than that of Saudi Arabia $39.3 \%{ }^{15}$ This difference in prevalence may be due to differences in the prevalence of obesity as mentioned earlier, sedentary lifestyle and physical inactivity. The frequency of MetS was three times more common among females than males, obesity (higher BMI), larger waist circumferences, higher systolic blood pressure, was higher among female participants as compared to male participants. A similar finding with the study of Lohsoonthorn et al. was noted. ${ }^{6}$ These may be related to hormonal changes, mainly progesterone which is increased during pregnancy, breastfeeding which increase the desire for taking sweets and more sedentary life among housewife females that constitute one-fourth of the participants in this study and found to constitute more than half of MetS prevalence with significant association between occupation and $\mathrm{MetS} .^{2}$ In this study, increasing age was associated with increasing of the prevalence of MetS with. A similar finding to Ervin et al. ${ }^{16}$ study which stated that age is an important independent risk factor for Mets.

Table 7: Family history by MetS.

\begin{tabular}{|c|c|c|c|c|c|c|c|}
\hline \multirow{2}{*}{\multicolumn{2}{|c|}{ Family history (FH) }} & \multicolumn{2}{|c|}{ MetS } & \multicolumn{2}{|c|}{ No MetS } & \multirow{2}{*}{ Total } & \multirow{2}{*}{$P$ value } \\
\hline & & No. & (\%) & No. & (\%) & & \\
\hline \multirow{3}{*}{ FH DM } & Yes & 74 & $(30.1)$ & 100 & $(69.9)$ & 174 & \multirow{3}{*}{0.029} \\
\hline & No & 108 & $(19.7)$ & 284 & $(80.3)$ & 392 & \\
\hline & Total & 182 & $(22.9)$ & 384 & $(77.1)$ & 566 & \\
\hline \multirow{3}{*}{$\mathrm{FHL}$} & Yes & 38 & (33.9) & 74 & $(66.1)$ & 112 & \multirow{3}{*}{$<0.001$} \\
\hline & No & 46 & $(18)$ & 209 & (82) & 255 & \\
\hline & Total & 84 & $(22.9)$ & 283 & $(77.1)$ & 367 & \\
\hline \multirow{3}{*}{ FH Obesity } & Yes & 99 & $(36.1)$ & 175 & (63.9) & 274 & \multirow{3}{*}{0.005} \\
\hline & No & 74 & $(25.3)$ & 218 & $(74.7)$ & 292 & \\
\hline & Total & 173 & $(30.6)$ & 393 & $(69.4)$ & 566 & \\
\hline \multirow{3}{*}{ FH HTN } & Yes & 111 & $(33.8)$ & 217 & $(66.2)$ & 328 & \multirow{3}{*}{0.047} \\
\hline & No & 62 & $(26.1)$ & 176 & $(73.9)$ & 238 & \\
\hline & Total & 173 & $(30.6)$ & 393 & $(69.4)$ & 566 & \\
\hline
\end{tabular}


There is an argue surrounding the etiology and pathogenesis of MetS, a single uniform mechanism needed to be discovered. ${ }^{2}$ However, multiple factors like hormonal, genetic and environmental (nutrition, body composition and stress hormones) factors play a key role in this contest. ${ }^{1}$ In this study, we have shown that family history of certain cardiovascular risk factors was associated with MetS including family history of DM, hyperlipidemia, of obesity and hypertension, the results found to be similar to Katzmaryk et al. $^{17}$ An INTERHEART study showed that cigarette smoking $59.9 \%$ associated with MetS in South Asia, ${ }^{18}$ but in our study no relation between cigarette smoking and MetS was found, possibly the frequency of smokers in this study was low 58/566 (10\%). Marital status was significantly associated with MetS, a figure similar to Thomas et al. ${ }^{19}$ and this may be due as stated above, the more advance in age the more prevalence of MetS. Education status from illiterate to university decreased the proportion of MetS, which is in line with Wamala et al., ${ }^{20}$ because education possibly makes the population more aware of their health.

\section{Conclusions}

Metabolic syndrome is prevalent among the studied population. Female gender, old age, family history of $\mathrm{DM}, \mathrm{HL}$, hypertension and obesity may be regarded as risk factors for MetS. People with these risk factors should be assessed for MetS and educated about the risks and possible consequences in the future.

\section{Conflicts of interest}

The authors report no conflicts of interest.

\section{References}

1. Campion J, Milagro FI. Individuality and epigenetics in obesity. Obes Rev 2009; 10: 383-92.

2. Ferrannini E. Metabolic syndrome: a solution in search of a problem. J Clin Endocrinol Metab2007; 92:396-8.

3. Danny E, Girish LK. Metabolic syndrome and cardiovascular disease in South Asians. Vasc Health Risk Manag 2009; 5:731-43.
4. Park HS, Kim SM. Prevalence and trends of metabolic syndrome in Korea: Korean National Health and Nutrition Survey 1998-2001. Diabetes Obes Metab2007; 9:50-8.

5. $\mathrm{MOH}, \mathrm{WHO}$. Chronic Non-communicable Diseases Risk Factor Survey in Iraq: A STEP wise Approach. Draft report; 2006. Available From: www.who.int/chp/steps/ IraqSTEPSReport2006.pdf. Accessed at $1^{\text {st }} \mathrm{Feb}$ 2013.

6. Lohsoonthorn V, Lertmaharit L. Prevalence of Metabolic Syndrome among Professional and Office Workers in Bangkok, Thailand. J Med Assoc Thai 2007; 90(9):1908-15.

7. WHO. Physical status: the use and interpretation of anthropometry. Geneva: WHO; 1995. [Report of a WHO Expert Committee] Technical Report Series, 854.

8. European Society of Cardiology. Guidelines for the management of dyslipidemias. Available From: www.escardio.org/guidelines Accessed at $2^{\text {nd }}$ Jan 2013.

9. International Diabetes Federation. The IDF Consensus worldwide definition of the metabolic syndrome. Available From: www.idf.org/metabolic -syndrome. Accessed at $7^{\text {th }}$ Jan 2013.

10. Chobanian AV, Bakris GL, Black HR, Cushman WC, Green LA, Izzo JL, et al. National Heart, Lung, and Blood Institute Joint National Committee on Prevention, Detection, Evaluation, and Treatment of High Blood Pressure; National High Blood Pressure Education Program Coordinating Committee. The Seventh Report of the Joint National Committee on Prevention, Detection, Evaluation, and Treatment of High Blood Pressure: the JNC 7 report. JAMA 2003; 289:2560-72.

11. National Heart, Lung, and Blood Institute. Fourth Report of the Expert Panel on Detection, Evaluation, and Treatment of High Blood Cholesterol in Adults (Adult Treatment Panel IV). Guidelines. From: www.nhlbi.nih.gov/files/docs/ resources/heart/atp3full.pdf. Accessed: Jan 2013.

12. National Institute for Health and Care Excellence (formerly National Institute for Health and Clinical Excellence): Guidance. Available From: http://www.ncbi.nlm.nih.gov/books/NBK11822/. Accessed at $8^{\text {th }}$ Feb 2013.

13. Misra A, Misra R, Wijesuriya M, Banerjee D. The metabolic syndrome in South Asians: continuing escalation and possible solutions. Indian J Med Res 2007; 125(3):345-54.

14. Zabetian A, Hadaegh F, Azizi F. Prevalence of metabolic syndrome in Iranian adult population, concordance between the IDF with the ATPIII and the WHO definitions. Diabetes Res Clin Pract 2007; 77:251-7.

15. Waleed I A. Helicobacter pylori infection and its relationship to metabolic syndrome: is it a myth or fact? Saudi J Gastroentrol 2011; 17:165-9.

16. Ervin RB. Prevalence of metabolic syndrome 
among adults 20 years of age and over, by sex, age, race and ethnicity, and body mass index: United States, 2003-2006. Nat Health Stat Report 2009; 13:1-7.

17. Katzmaryk PT. Targeting the Metabolic Syndrome with Exercise: Evidence from the HERITAGE Family Study. Med Sci Sports Exerc 2003; 35(10):1703-9.

18. Danny E, Girish LK, Nadya M, Anjali A, Bobby VK. Metabolic syndrome and cardiovascular disease in South Asians. Vasc Health Risk Manag 2009; 5:731-43.

19. Thomas GN, Ho SY, Janus ED, Lam KS, Hedley AJ, Lam TH. The US National Cholesterol Education Program Adult Treatment Panel III (NCEP ATP III) prevalence of the metabolic syndrome in a Chinese population. Diabetes Res Clin Pract 2005; 67:251-7.

20. Walmala SP, Lynch J, Horstan M, Mittleman MA, Schenck-Gustafsson K, Orth-Gom'er K. Education and metabolic syndrome. Diabetes care 1999; 22:1999-2003. 